\title{
The Comparison of the Effectiveness of Local Ice and Manual Pressure Applications in Decreasing Pain Related to Intramuscular Injection
}

\author{
Sebnem Bilgic \\ Faculty of Health Sciences, Fundamentals of Nursing Department, Trakya University, Edirne, Turkey. \\ Correspondence Author: Sebnem Bilgic \\ E-mail: sebnembilgic@trakya.edu.tr \\ Received: $10.08 .2020 \quad$ Accepted: 15.03 .2021
}

\begin{abstract}
Objective: Because of the pain they cause, intramuscular (IM) injection applications can constitute a negative experience for both the patients and the nurses performing the application. This study was planned to compare the effectiveness of local ice and manual pressure applications in decreasing the injection pain experienced by patients.

Methods: This study performed a university hospital in Turkey. One hundred and thirty five patients, 45 in the local ice group, 45 in the manual pressure group and 45 in the control group, met the inclusion criteria and completed the study. The local ice group received cold ice application to the injection area before injection. The manual pressure group received pressure applied by the researcher to the injection area before injection. The control group received routine injection. Study data was collected using the Wong-Baker FACES Pain Rating Scale (WBS) and the Visual Analog Pain Scale (VAS).

Results: As a result of the study, no difference was found between the groups in which manual pressure and local ice applications were applied. However, a statistically significant difference was found between the experimental groups (manual pressure and local ice) and the control group. The mean \pm standard deviation WBS and VAS scores of the control group $(2.22 \pm 0.84$ and $13.13 \pm 13.49$, respectively) were statistically significantly higher than the groups in which manual pressure $(1.82 \pm 0.80$ and $8.11 \pm 9.13$, respectively) and local ice $(1.80 \pm 0.69$ and $7.26 \pm 4.98$, respectively) were applied.

Conclusions: It was concluded that local ice and manual pressure applications before IM injections were effective in decreasing the injection pain of patients.

Keywords: Injections, injection pain, local ice, manual pressure, pain control.
\end{abstract}

\section{INTRODUCTION}

Injections are considered the gold standard in the parenteral application of various drugs (1). Intramuscular (IM) injection, which is one of the parenteral applications, is used worldwide commonly. IM injection is often preferred in the application of drugs such as antibiotics, vitamins, and painkillers (2). However, if the area is not appropriately determined in IM injection treatments or if the injection is not performed with the appropriate technique, serious complications may arise (3). The most common among these complications is pain, and this may arise as a result of not choosing the appropriate area, the injector penetrating the skin, and the mechanic and chemical effects of the drug during and after injection $(1,4)$.

Pain, which is an unwanted experience for any patient, is defined as the fifth symptom of life and thus its management is important regardless of the pain being acute or chronic $(5,6)$. IM injection pain not managed properly can cause fear of injection to arise in patients. As a result, the quality of life of the patient can be negatively affected or patients may delay seeking medical attention (6,7). Additionally, painful injections can harm the relationship between patients and nurses $(8,9)$ For this reason, it is important for nurses to manage injection pain with appropriate interventions (10). In order to manage pain properly, nurses first need to know the pain, the factors affecting the pain, genetic or ethnic predilection, and pain tolerance. It is important for nurses to evaluate their patients, choose the most appropriate evidence based intervention, apply it to the patient, and observe the results (6).

The right to ease pain is one of the most basic human rights (10). Many different methods have been tried throughout the centuries to ease injection pain. Applications of pressure and ice are also among these methods $(11,12)$. In pressure application, the pressure applied has been 
reported to cause beta endorphin to be released into the bloodstream in the area, easing pain. According to the door control theory, pain senses in the back horn of the spinal cord are inhibited by pressure, decreasing pain (13). In ice application, the conduction speed of the nerves in the area is decreased, slowing down the conduction of pain signals, increasing the pain threshold, and causing a decrease in pain intensity $(12,14)$. These interventions, which can be used by nurses to decrease pain during injection, can be sued in clinical application without any additional cost or loss of time (11).

Applications towards easing pain can help patients to cope with this situation better. There are studies in the literature showing that pressure $(10,11,15,16)$ and ice applications $(8,12,14)$ care effective in decreasing injection pain. However, no studies comparing the effectiveness of manual pressure and ice applications could be found. For this reason, this study was planned to compare the effectiveness of local manual ice and pressure applications in decreasing the injection pain experienced by patients.

\section{METHODS}

\subsection{Aim of the Study}

This is a non-randomized (quasi-experimental) study planned to compare the effectiveness of local ice and manual pressure applications in decreasing the injection pain experienced by patients.

\subsection{Setting and Sample}

The universe of this study, which was performed between September $10^{\text {th }} 2016$ and March 10 $0^{\text {th }}$ 2017, consisted of the inpatients in the obstetrics service of a university hospital. The sample size of the study was calculated using the power analysis method. In the calculation performed by taking into account the parameters of the groups, 126 patients were found to be sufficient with a 0.80 power rating, a 0.05 error rate, and a 0.95 effect level. Taking possible losses into account, assigning 45 patients each to the local ice, manual pressure, and control groups was found appropriate.

Factors that may affect the pain experience of the individuals were taken into consideration in the selection of the sample. In order to eliminate the effect of gender on the pain experience of the patients and to standardize the application, only female patients were studied. Because the biological and psychosocial conditions of the individuals may affect the intensity, frequency and duration of the pain, patients with communication problems, very fat or thin patients, lesions at the injection site, and severe pain before injection were not included in the study. Patients who received the same treatment were selected for the study in order to standardize other factors that may affect the individual's perception of pain, such as injection speed, needle temperature and the content of injected fluids. And all patients were performed under the same conditions as a single operator. In addition, the ventrogluteal region was preferred because it is a reliable IM injection site away from nerves, bones and blood vessels. In this context, the sample of the study consisted of patients who were on IM diclofenac sodium treatment in their routine treatment, who were older than 18 years of age, who had no communication problems, were not too fat or thin (body mass index 18-30), had no lesions at the injection site, did not have severe pain before injection (VAS score $<8$ ), and were willing to participate in the study. Also, 9 patients who were obese $(n=6)$ and had a preoperative pain score greater than $8(n=3)$ were not included in the study.

\subsection{Study Hypotheses}

Hypothesis $\left(\mathrm{H}_{0}\right) 1$ : There is no difference between manual pressure application and local ice application in reducing pain associated with intramuscular injection application.

Hypothesis $\left(H_{1}\right) 1$ : There is a difference between manual pressure application and local ice application in reducing pain associated with intramuscular injection application.

Hypothesis $\left(H_{0}\right) 2$ : Local ice application is not effective in reducing pain associated with intramuscular injection application.

Hypothesis $\left(\mathrm{H}_{1}\right)$ 2: Local ice application is effective in reducing pain associated with intramuscular injection application.

Hypothesis $\left(\mathrm{H}_{0}\right)$ : Manual pressure application is not effective in reducing pain associated with intramuscular injection application.

Hypothesis $\left(\mathrm{H}_{1}\right) 3$ : Manual pressure application is effective in reducing pain associated with intramuscular injection application.

\subsection{Measurement}

Study data was collected using a General Information Form, The Wong-Baker FACES Pain Rating Scale (WBS), and The Visual Analog Pain Scale (VAS).

\subsubsection{The General Information Form}

This form was prepared by the researcher according to literature $(11,14,17)$, and consisted of demographic characteristics such as age, gender, marital status, pain tolerance, fear of injection, as well as vital findings (blood pressure, and pulse)

\subsubsection{The Wong-Baker FACES Pain Rating Scale (WBS)}

The WBS was developed by Wong and Baker in 1988. This is scale where facial expressions rated between 0 and 5 are used to determine the pain levels of the patients. In the scale, "0" terms "No pain", "1" terms "a little pain", "2" terms "more pain", " 3 " terms "moderate pain" " 4 " terms "intense 
pain" and " 5 " terms "The most intense pain possible". In the scoring performed using facial expressions, the expressions change with increasing scores, which in turn terms an increase in pain levels (18).

\subsubsection{The Visual Analog Pain Scale (VAS)}

This scale, which is used to evaluate the pain experienced by patients, consists of a horizontal line scored between 0 and 10. The value of 0 terms no pain while the value 10 terms the most intense pain possible.

\subsection{Data Collection}

The patients, who were being treated in the service where the study was conducted and would undergo IM diclofenac sodium treatments by doctor's orders, were informed on the aim, context, duration, and method of the study. After being informed, the patients who volunteered to participate in the study gave written consent and were included in the sample. Among the inpatients, the first patient was assigned to the local ice application group, the second patient to the manual pressure application group, and the third patient to the control group. The patients were introduced to the VAS before injection, taught how to mark the VAS, and their blood pressures and pulses were measured by the researcher and noted on the general information form. In the injection application, the ventrogluteal area was preferred since it is the safest injection area $(3,19)$. All injection applications were performed by the researcher. For data reliability, two observers were present in each application. The following steps were used for data collection.

The preparation of the diclofenac sodium before injection: The solution, in the form of a $75 \mathrm{mg} / 3 \mathrm{~mL}$ ampoule, was prepared using a $5 \mathrm{~mL}, 21$ gauge, $38 \mathrm{~mm}$ injector. The injector tip was changed after drawing the drug into the injector.

The local ice application group: Patients in this group underwent cold application to the injection area before injection for 30 seconds using a $3 \times 3 \times 3 \mathrm{~cm}$ ice cube. The area was then wiped with an alcohol swab, and injection was performed after the area dried $(8,20)$.

The manual pressure application group: Patients in this group underwent 10 seconds of pressure applied by the researcher to the injection area before injection with the thumb of the passive hand at a strength sufficient to feel resistance. The area was then wiped with an alcohol swab, and injection was performed after the area dried $(11,14,21)$.

The control group: No application was performed before injection.

After the injection: The patients were asked to evaluate their pain using the VAS. The pain levels of the patients were evaluated by the researcher and the two observers using the WBS.

\subsection{Ethical Considerations}

Before the study, written permission from the institutions where the study was conducted and ethical approval from the Namık Kemal University School of Medicine NonInvasive Clinical Studies Board of Ethics were received (2016/61/04/10). Institutional permission from the hospital where the study would be conducted was taken, as well as written consent from the patients who agreed to participate in the study.

\subsection{Data Analysis}

The analysis of the data obtained from the study was performed using the SPSS (Statistical Package for Social Science) 22.0 package program. Descriptive statistics, such as mean, standard deviation (SD), number, and frequency, were used to characterize the research participants. Kolmogorov-Smirnov test was used for normality distribution of variables. Chi-square and one-way ANOVA tests were used to evaluate the similarity of the groups. One-way ANOVA and Tukey tests were used to determine the difference between groups. A $p$ value of $<0.05$ was considered statistically significant.

\section{RESULTS}

The mean $\pm S D$ age of the patients who participated in the study was $36.64 \pm 12.18$ (range: $18-65$ ). $93.3 \%$ of the patients were married and $63.0 \%$ were elementary school graduates. $55.6 \%$ of the patients stated that they had middle levels of pain tolerance, $69.6 \%$ stated that they did not fear IM injection, and $85.2 \%$ stated that they never had a negative experience regarding IM injection applications. The mean $\pm S D$ pulse of the patients was $79.62 \pm 8.32$ beats per minute, their mean \pm SD systolic blood pressure was $108.00 \pm 10.05 \mathrm{mmHg}$, and their mean $\pm S D$ diastolic blood pressure was $67.81 \pm 7.21$ $\mathrm{mmHg}$. No statistically significant difference regarding these characteristics was found among the groups, showing that the patients in the three groups were distributed similarly (p>0.05) (Table 1).

When the mean $\pm S D$ WBS and VAS scores of the control (2.22 \pm 0.84 and $13.13 \pm 13.49$, respectively), manual pressure $(1.82 \pm 0.80$ and $8.11 \pm 9.13$, respectively), and local ice $(1.80 \pm 0.69$ and $7.26 \pm 4.98$, respectively) groups were compared, a statistically significant difference among the groups with regard to mean WBS and VAS scores was found. The difference in the WBS and VAS mean scores was found to be between the control group and the study groups, where the control group received a higher score compared to the groups which underwent pressure and ice applications $(p<0.05)$ (Table 2). 
Table 1. Comparison of the descriptive characteristics between manuel pressure, local ice and control groups ( $\mathrm{N}=135)$

\begin{tabular}{|c|c|c|c|c|c|c|c|c|}
\hline \multirow[b]{2}{*}{$\begin{array}{l}\text { Marital Status } \\
\text { Married } \\
\text { Single }\end{array}$} & \multicolumn{2}{|c|}{$\begin{array}{c}\text { Control Group (n:45) } \\
\text { N \% }\end{array}$} & \multicolumn{2}{|c|}{$\begin{array}{l}\text { Manuel Pressure Group } \\
\qquad \begin{array}{c}\text { (n:45) } \\
\text { N } \%\end{array}\end{array}$} & \multicolumn{2}{|c|}{$\begin{array}{l}\text { Lokal Ice Group (n:45) } \\
\text { N \% }\end{array}$} & $\begin{array}{c}\text { Total } \\
\text { (N:135) } \\
\text { N \% }\end{array}$ & \multirow{2}{*}{$\begin{array}{c}\chi 2^{*} F^{* *} \\
p \\
5000 \\
0.083^{*}\end{array}$} \\
\hline & $\begin{array}{r}43 \\
2\end{array}$ & $\begin{array}{l}95.6 \\
4.4\end{array}$ & $\begin{array}{r}44 \\
1\end{array}$ & $\begin{array}{l}97.8 \\
2.2\end{array}$ & $\begin{array}{c}39 \\
6\end{array}$ & $\begin{array}{l}86.7 \\
13.3\end{array}$ & $\begin{array}{cl}126 & 93.3 \\
9 & 6.7\end{array}$ & \\
\hline $\begin{array}{l}\text { Education } \\
\text { Literacy } \\
\text { Elementary school } \\
\text { High school } \\
\text { University }\end{array}$ & $\begin{array}{r}7 \\
27 \\
5 \\
6\end{array}$ & $\begin{array}{l}15.6 \\
60.0 \\
11.1 \\
13.3\end{array}$ & $\begin{array}{r}3 \\
29 \\
6 \\
7\end{array}$ & $\begin{array}{l}6.7 \\
64.4 \\
13.3 \\
15.6\end{array}$ & $\begin{array}{c}6 \\
29 \\
5 \\
5\end{array}$ & $\begin{array}{c}13.3 \\
64.4 \\
11.1 \\
11.1\end{array}$ & $\begin{array}{ll}16 & 11.9 \\
85 & 63.0 \\
16 & 11.9 \\
18 & 13.2\end{array}$ & $\begin{array}{c}2.177 \\
0.533^{*}\end{array}$ \\
\hline $\begin{array}{l}\text { Tolerence to Pain } \\
\text { High } \\
\text { Middle } \\
\text { Low }\end{array}$ & $\begin{array}{c}8 \\
27 \\
10\end{array}$ & $\begin{array}{l}17.8 \\
60.0 \\
22.2\end{array}$ & $\begin{array}{r}15 \\
22 \\
8\end{array}$ & $\begin{array}{l}33.3 \\
48.9 \\
17.8\end{array}$ & $\begin{array}{c}10 \\
26 \\
9\end{array}$ & $\begin{array}{l}22.2 \\
57.8 \\
20.0\end{array}$ & $\begin{array}{ll}33 & 24.4 \\
75 & 55.6 \\
27 & 20.0\end{array}$ & $\begin{array}{c}3.146 \\
0.354^{*}\end{array}$ \\
\hline $\begin{array}{l}\text { Fear of Injection } \\
\text { Yes } \\
\text { No }\end{array}$ & $\begin{array}{l}14 \\
31\end{array}$ & $\begin{array}{l}31.1 \\
68.9\end{array}$ & $\begin{array}{l}17 \\
28\end{array}$ & $\begin{array}{l}37.8 \\
62.2\end{array}$ & $\begin{array}{l}10 \\
35\end{array}$ & $\begin{array}{l}22.2 \\
77.8\end{array}$ & $\begin{array}{ll}41 & 33.4 \\
94 & 69.6\end{array}$ & $\begin{array}{c}2.592 \\
0.278^{*}\end{array}$ \\
\hline $\begin{array}{l}\text { Bad Experience with Injection } \\
\text { Yes } \\
\text { No }\end{array}$ & $\begin{array}{c}8 \\
37\end{array}$ & $\begin{array}{l}17.8 \\
82.2\end{array}$ & $\begin{array}{c}6 \\
39\end{array}$ & $\begin{array}{l}13.3 \\
86.7\end{array}$ & $\begin{array}{r}6 \\
39\end{array}$ & $\begin{array}{l}13.3 \\
86.7\end{array}$ & $\begin{array}{ll}20 & 14.8 \\
115 & 85.2\end{array}$ & $\begin{array}{c}0.470 \\
0.795^{*}\end{array}$ \\
\hline $\begin{array}{l}\text { Age (year) Mean } \pm S D \\
\text { (min-max) }\end{array}$ & $\begin{array}{r}36.6 \\
(2\end{array}$ & $\begin{array}{l} \pm 12.21 \\
-65)\end{array}$ & $\begin{array}{r}34.51 \\
(19\end{array}$ & $\begin{array}{l} \pm 11.58 \\
-63)\end{array}$ & $38.77 \pm 1$ & $63(18-65)$ & $\begin{array}{c}36.64 \pm 12.18 \\
(18-65)\end{array}$ & $\begin{array}{c}1.400 \\
0.253^{* *}\end{array}$ \\
\hline $\begin{array}{l}\text { Pulse number/minutes Mean } \pm S D \\
\text { (min-max) }\end{array}$ & $\begin{array}{r}78.4 \\
16\end{array}$ & $\begin{array}{l}4 \pm 7.75 \\
1-96)\end{array}$ & $\begin{array}{r}80.0 \\
167\end{array}$ & $\begin{array}{l}5 \pm 7.62 \\
-98)\end{array}$ & $\begin{array}{r}80.3 \\
16\end{array}$ & $\begin{array}{l} \pm 9.53 \\
-98)\end{array}$ & $\begin{array}{c}79.62 \pm 8.32 \\
(60-98)\end{array}$ & $\begin{array}{c}1.063 \\
0.506^{* *}\end{array}$ \\
\hline $\begin{array}{l}\text { Systolic Blood Pressure }(\mathrm{mmHg}) \\
\text { Mean } \pm \text { SD } \\
\text { (min-max) }\end{array}$ & $107.11 \pm 10$ & $.57(90-130)$ & $\begin{array}{r}107.5 \\
(90\end{array}$ & $\begin{array}{l} \pm 10.47 \\
-130)\end{array}$ & $\begin{array}{r}109 . \\
(80\end{array}$ & $\begin{array}{l}3 \pm 9.14 \\
130)\end{array}$ & $\begin{array}{c}108.00 \pm 10.05 \\
(80-130)\end{array}$ & $\begin{array}{c}0.703 \\
0.544^{* *}\end{array}$ \\
\hline $\begin{array}{l}\text { Diastolic Blood Pressure }(\mathrm{mmHg}) \\
\text { Mean } \pm \mathrm{SD} \\
\text { (min-max) }\end{array}$ & $65.88 \pm 6$ & $84(50-80)$ & $\begin{array}{r}68.0 \\
(50\end{array}$ & $\begin{array}{l} \pm 7.93 \\
-90)\end{array}$ & $\begin{array}{r}69.5 \\
(5\end{array}$ & $\begin{array}{l} \pm 6.46 \\
-80)\end{array}$ & $\begin{array}{l}67.81 \pm 7.21 \\
\quad(50-90)\end{array}$ & $\begin{array}{c}2,843 \\
0.053^{* *}\end{array}$ \\
\hline
\end{tabular}

* Chi-square Test; **One-way ANOVA

Table 2. Intergroup comparison of WBS and VAS mean scores of experimental and control groups $(N=135)$

\begin{tabular}{|c|c|c|c|c|c|}
\hline & $\begin{array}{c}\text { Control Group } \\
\text { (n:45) } \\
\text { Mean } \pm \text { SD }\end{array}$ & $\begin{array}{c}\text { Manuel Pressure } \\
\text { Group(n:45) } \\
\text { Mean } \pm \text { SD }\end{array}$ & $\begin{array}{l}\text { Lokal Ice Group } \\
\text { (n:45) } \\
\text { Mean } \pm \text { SD }\end{array}$ & $\begin{array}{c}\text { Total } \\
\text { (N:135) } \\
\text { Mean } \pm \text { SD }\end{array}$ & $\mathbf{F}$ \\
\hline WBS & $2.22 \pm 0.84$ & $1.82 \pm 0.80$ & $1.80 \pm 0.69$ & $1.94 \pm 0.80$ & $\begin{array}{c}4.1120 .019^{*} \\
1>2 \text { ve } 3^{* *}\end{array}$ \\
\hline VAS & $13.13 \pm 13.49$ & $8.11 \pm 9.13$ & $7.26 \pm 4.98$ & $9.50 \pm 10.10$ & $\begin{array}{c}4.6760 .011^{*} \\
1>2 \text { ve } 3^{* *}\end{array}$ \\
\hline
\end{tabular}

* One-way ANOVA. ** Tukey Test; WBS: The Wong-Baker FACES Pain Rating Scale VAS: The Visual Analog Pain Scale, 1=Control Group, 2= Manuel Pressure Group, 3= Local Ice Group

\section{DISCUSSION}

IM injection is and invasive and painful drug treatment (8). It is the nurse's responsibility to apply a good injection technique and the best approach to pain management to prevent and alleviate injection-related pain (22). Different methods can be used to reduce the pain associated with injection. In this study, the effects of manual pressure and local ice application on injection pain were compared. As a result in this study, the pain levels of the patients were evaluated both through the observations of the researchers (WBS) and the self-reports of the patients (VAS). In the evaluation based on researcher observation and patients self-reports, no statistically significant difference between the study groups could be found with regard to the pain experiences of the patients, while a statistically significant difference between the study groups and the control group was found. Local ice and manual pressure applications were found to be effective in decreasing the pain levels of patients compared to the control group. According to these results, it was concluded 
that local ice and manual pressure applications before IM injection were effective in decreasing the injection pain levels of patients.

When the literature on local ice application is examined, it is seen that the results are similar. In a study conducted by Hasanpour et al. with 90 child patients undergoing intramuscular penicillin injections, the patients were separated into local ice, distraction, and control groups, and the pain levels of the children were measured using the Oucher Scale. As a result of the study, the pain experiences of the distraction and local ice groups were concluded to be less compared to the control group, and non-pharmacological pain management methods were found to be effective (16). In a study where Farhadi and Esmailzadeh examined the effect of local cold application before intramuscular penicillin injection on pain intensity, adult patients in the study group underwent local ice application before injection. As a result of the study, where the pain experiences of the patients were evaluated using the VAS, the injection related pain of the patients who underwent local ice application was found to be significantly lower. It was thus concluded that applying ice locally before penicillin injections could play an important role in decreasing pain (8). In the study conducted by Ramadan et al. on adult patients, it was found that the group who had 30 seconds of local ice application before IM injection had statistically lower pain score due to injection than the patients who did not apply ice (23). In another study conducted by Ramadan et al., it was found that patients who had ice application before IM injection had a decrease in pain due to injection, and ice application was recommended before IM injection (24). In another study, it was stated that cold application for 5 seconds before IM injection was effective in reducing pain due to injection (25). Similarly, in another study by Bilge et al., they used cold spray for ice effect. After the application, they found that the cold spray was an effective attempt to reduce the pain associated with IM injection (26). Additionally, it has been reported in literature that beside its pain decreasing effects, cold applications could cause vasoconstriction and delays in the absorption of the drug, and that this should be taken into consideration in patients where the absorption of the drug needs to be fast (27).

When the studies on manual pressure were examined, the results were found to be similar. In studies conducted by Nasiry et al. with adult patients and Derya et al. with children, the effect of manual pressure application on IM injection pain was evaluated. Manual pressure was applied to the injection area before intervention and the pain levels of the patients were evaluated using the VAS. As a result of those studies, manual pressure application was found to be effective in decreasing the pain perceived by both children and adults compared to the routine application, and this method was suggested for routine use $(11,19)$. In a study where Öztürk et al. evaluated the effect of manual pressure application on injection pain in university students, 123 students underwent IM Hepatitis $A$ and $B$ vaccine applications. Students in the study group underwent 10 seconds of manual pressure application to the injection area before injection and the pain experiences of the students were evaluated using the numerical rating scale. As a result of the study, students who underwent the manual pressure application were reported to experience less pain, and the application was suggested for use in adults before IM injection (21). In another study conducted by Çelik in patients who received IM penicillin, manual pressure was found to be effective in reducing injection-related pain (28).

\section{CONCLUSION}

Although there are studies in the literature evaluating the effectiveness of manual pressure and local ice applications, no studies comparing the effectiveness of those methods could be found.

In the present study, unlike the literature, the efficiency of the two applications was compared and it was found that there was no difference between the two applications. However, a significant difference was found between the intervention groups and the control group. According to these results, it can be suggested that nurses should utilize local ice and manual pressure applications before IM injection treatments to decrease the pain levels of patients. These physical pre injection applications are thought to be preferable for no additional cost or loss of time, ease and safety of use, and not requiring special training or skill. Performing applications that would minimize the pain of patients in painful interventions such as IM injection would positively affect patient satisfaction, quality of life, and comfort.

Since this study was conducted with a specific group of patients in a single clinic with a small sample size, the results of the study cannot be generalized for all patients. In this study, it was impossible to accomplish a true double - blinded study with manual pressure, local ice therapy or routine injecting as it was obvious to the patients which intervention they were receiving. Pain data being collected not through objective measurements but through patient self-reporting and observation constitutes another limitation of the study. Repeating the study with larger groups to confirm the results is thus suggested.

\section{REFERENCES}

[1] Kanika K, Prasad S. Effect of massage on pain perception after administration of intramuscular injection among adult patients. Nurs Midwifery Res J 2011; 7(3):130-138.

[2] Raddadi Y, Adib-Hajbaghery M, Ghadirzadeh Z, Kheirkhah D. Comparing the effects of acupressure at LI4 and BL32 points on intramuscular injection pain. Eur J Integr Med 2017; 11:6368.

[3] Ogston-Tuck S, Worcester W, Mueller's RS. Intramuscular injection technique: an evidence-based approach. Nurs Stand 2014; 29(4):52-59.

[4] Güneş ÜY, Kara D, Arı S, Ceyhan O. Which site is more painful in intramuscular injections? The dorsogluteal site or the ventrogluteal site? A case study from Turkey. Clin Nurs Stud 2013; 1(4):74-81 
[5] Aydin D, Şahiner NC, Çiftçi EK. Comparison of the effectiveness of three different methods in decreasing pain during venipuncture in children: ball squeezing, balloon inflating and distraction cards. J Clin Nurs 2016; 25(15-16):2328-2335.

[6] Ozdemir L, Punarcl E, Akay BN, Akyol A. Effect of methylprednisolone injection speed on the perception of intramuscular injection pain. Pain Manag Nurs 2013; 14(1):310.

[7] Suhrabi Z, Taghinejad H. Effect of acupressure (UB32) on pain intensity in intramuscular injections. Iran J Nurs Midwifery Res 2014; 19(1):24-27.

[8] Farhadi A, Esmailzadeh M. Effect of local cold on intensity of pain due to Penicillin Benzathin intramuscular injection. Int J Med Med Sci 2011; 3(11):343-346.

[9] Najafi SS, Nazaribin S, Momennasab M, Yoosefinejad AK. The effect of manual acupressure (point UB32) on pain associated with intramuscular injections of magnesium sulfate. J Acupunct Meridian Stud 2018; 1-6.

[10] Zore G, Ragina D. Effectiveness of nursing interventions on pain associated with intramuscular injection. Int J of Sci and Res 2014; 3:1995-2000.

[11] Derya EY, Karabacak U, Yavuz T, Izzet AY. Applying manual pressure before benzathine penicillin injection for rheumatic fever prophylaxis reduces pain in children. Pain Manag Nurs 2015; 16(3):328-335.

[12] Attia AAM, Hassan AM. Effect of cryotherapy on pain management at the puncture site of arteriovenous fistula among children undergoing hemodialysis. Int J Nurs Sci 2017; 4(1): 46-51.

[13] Bastami M, Azadi A, Mayel M. The use of ice pack for pain associated with arterial punctures. J Clin Diagn Res 2015; 9(8):JC07-JC09.

[14] Chung JW, Ng WM, Wong TK. An experimental study on the use of manual pressure to reduce pain in intramuscular injections. J Clin Nurs 2002; 11(4):457-461.

[15] Gülnar E, Özveren H. An evaluation of the effectiveness of a planned training program for nurses on administering intramuscular injections into the ventrogluteal site. Nurse Educ Today 2016; 36:360-363.

[16] Hasanpour M, Tootoonchi M, Aein F, Yadegarfar G. The effects of two non-pharmacologic pain management methods for intramuscular injection pain in children. Acute Pain 2006; $8(1): 7-12$
[17] Kant E, Akpinar RB. The effect of music and the pressure applied on pain induced by intramuscular injection. Int J Caring Sci 2017; 10(3):1313-1318.

[18] Wong DL, Baker CM. Pain in children: comparison of assessment scales. Pediatr Nurs 1988; 14(1):9-17.

[19] Nasiry H, Hesam M, Asayesh H, Rahmani Anaraki H, Shariati $\mathrm{K}, \mathrm{A}$ Bathai $\mathrm{S}$. The effect of manual pressure on intramuscular injection pain severity. J Urmia Nurs Midwifery Fac 2013; 11(2):113-118.

[20] Yıldız T. Çocuklarda İntramüsküler Penisilin Enjeksiyonu Ağrısına Lokal Buz Uygulamasının Etkisi. Haliç Üniversitesi. Sağlık Bilimleri Enstitüsü, Yüksek Lisans Tezi. 2014. (Turkish)

[21] Öztürk D, Baykara ZG, Karadag A, Eyikara E. The effect of the application of manual pressure before the administration of intramuscular injections on students' perceptions of postinjection pain: a semi-experimental study. J Clin Nurs 2017; 26(11-12):1632-1638.

[22] Karabey T, Karagözoğlu Ş. Use of non-pharmacological methods for pain control in Intramuscular injection applications: a systematic review. IOSR-JNHS 2020; 9(2):1-6.

[23] Ramadan RH, Soliman HM, Othman WN. Effect of cryotherapy versus heifer technique on pain intensity among adult patients receiving Intramuscular Injection. IOSR-JNHS 2018; 7(6):79-95.

[24] Ramadan RH, El-Fouly YA, Sharaf WE, Ayoub AS. Effect of cryotherapy on pain intensity among adult patients receiving Intramuscular injections. IOSR-JNHS 2016; 5(2):01-10.

[25] Kalyan K, Shahji J, Kumari S, Kumari R. A study to assess the effectiveness of local cold application prior to intramuscular Injection for reducing needle stick pain among the patients in selected hospitals at Amritsar. Int J of Nurs Crit Care 2019; 5(2):48-54.

[26] Bilge S, Aydin A, Gun C, Aldinc H, Acar YA, Yaylaci S, Balci V. Comparison of the efficacy of Shot Blocker and cold spray in reducing intramuscular injection-related pain in adults. Saudi Med J 2019; 40(10):996-1002.

[27] Schechter NL, Zempsky WT, Cohen LL, McGrath PJ, McMurtry $\mathrm{CM}$, Bright NS. Pain reduction during pediatric immunizations: evidence-based review and recommendations. Pediatrics 2007; 119(5):e1184-e1198.

[28] Çelik Ş. İntramüsküler Penisilin Enjeksiyonu Uygulanacak Bölgeye Manuel Basınç Uygulamanın Enjeksiyon Ağrısı Üzerine Etkisi. Atatürk Üniversitesi. Sağlık Bilimleri Enstitüsü, Yüksek Lisans Tezi. 2020. (Turkish) 